\title{
Functional outcomes and complications of simultaneous bilateral total hip arthroplasty in Asian population
}

\author{
Ram Prasad Meena, Utsav Shetty*, Sadaram Bishnoi, Ramkhiladi Meena
}

Department of Orthopaedics, Government Medical College, Kota, Rajasthan, India

Received: 20 November 2019

Revised: 15 January 2020

Accepted: 22 January 2020

*Correspondence:

Dr. Utsav Shetty,

E-mail: shetty.utsav@gmail.com

Copyright: (C) the author(s), publisher and licensee Medip Academy. This is an open-access article distributed under the terms of the Creative Commons Attribution Non-Commercial License, which permits unrestricted non-commercial use, distribution, and reproduction in any medium, provided the original work is properly cited.

\begin{abstract}
Background: Total hip arthroplasty (THA) is one of the most successful and cost-benefit surgical treatments. However, there are concerns about the safety of the procedure and higher complications. We aimed to evaluate the complications and outcomes of one-stage bilateral total hip arthroplasty (BTHA) with anterolateral approach.

Methods: A total of 24 patients from February 2014 to October 2019 underwent BTHA in Government Medical College and Attached Group of Hospitals, Kota. A prospective analysis of the functional outcomes and complications was performed. All surgeries were performed via anterolateral approach. All patients were followed up till 1.5 years post-operative.

Results: During period of study 16 men and 8 women with a mean age of $40.12 \pm 2.52$ years at the time of presentation were entered. The mean surgical time was $112 \pm 6$ mins. The mean hospital stay was 7 days. Hemoglobin level decreased significantly after operation $(\mathrm{p}=0.046)$ mean of $10.83 \pm 0.3 \mathrm{mg} / \mathrm{dl}$. There was no reported patient with perioperative death, deep venous thrombosis, pulmonary embolism, infection, dislocation, periprosthetic fracture or heterotrophic ossification. The mean preoperative MHHS score was $45.93 \pm 5.33$ in patients. MHHS score improved to $92.06 \pm 2.47$ in the last follow-up $(\mathrm{p}=0.0001)$.

Conclusions: Our results recommend the use of one-stage BTHA through anterolateral approach in cases indicating bilateral THA without increase in rate of complications. Functional and clinical outcomes are comparable and hospital stay is significantly shorter.
\end{abstract}

Keywords: One stage bilateral total hip arthroplasty, Clinical outcome, Complication

\section{INTRODUCTION}

Total hip arthroplasty (THA) is evolving continuously and is one of the most successful orthopaedic surgeries around the world. There has been a lot of debate about performing simultaneous bilateral hip arthroplasty with relation to its intra operative and post-operative complications. A bilateral THA is required in around 15$25 \%$ of patients. The optimal timing of surgery in patients requiring surgery is controversial. In spite of the considerable number of studies regarding bilateral THA, controversy has prevailed and many surgeons are concerned about major perioperative complications. Bilateral THA as a single staged procedure has been described. ${ }^{1-4}$ But concerns have been expressed about the increased incidence of deep-vein thrombosis heterotopic ossification, a reduced range of movement, a suboptimal gain in walking ability, and the mortality and morbidity in patients with medical problems. ${ }^{1,2,5,6}$ If a controlled study comparing patients with bilateral total hip replacements as a single operation and patients with unilateral total hip replacements were to demonstrate 
little or no increase in morbidity, mortality or the duration of postoperative rehabilitation with the simultaneous procedure, then that operation would seem to be a reasonable choice for patients with bilateral hip disease. Here we conducted this study of simultaneous bilateral procedure to compare and deduce the complications, benefit and functional outcomes of the surgery.

\section{METHODS}

After obtaining institutional ethical board clearance, we conducted a prospective interventional, non-comparative study at Government medical college and associated group of hospitals, Kota, Rajasthan, from February 2014 to October 2019 consisting of 24 consecutive patients with bilateral total hip replacements as a single operation were considered. Patients with bilateral osteoarthritis hip joint, bilateral AVN hip and bilateral ankylosing spondylitis. We excluded patients with a 4 or higher grading of American Society of Anaesthesiologists (ASA) grading system, bony ankylosis, severe deformities in bilateral hips, significant knee and/or spine involvement, the latter group of patients was excluded because such patients might experience difficulties in post-operative functional recovery, making comparison difficult. Patients' age, etiology of hip disease and total hip prosthesis used were recorded. The age and gender distribution of patients, level of the hemoglobin and hematocrit, limb-length discrepancy, Charnley functional class, VAS score and the Harris hip score (HHS) were recorded pre-operatively. Patient's fitness was categorized according to ASA grading from grade 1 - 4, grade 1 and 2 were considered as low risk patients and grade 3 and 4 as high-risk patients.

Since the beginning of this study, all patients for whom bilateral total hip replacement was judged, underwent the bilateral procedure under one anesthetic. No individuals were excluded from this study due to their age, severe flexion contracture, etiology and severity of the hip disease, or underlying medical problems. All procedures were performed or supervised by the senior surgeon. They were compared in terms of length of hospitalization and operating time, type of anticoagulant used and method of administration, units of blood transfusions to the patient in the operating room, the recovery room, and in the ward, and follow-up evaluations after a minimum of 1.5 years. All hip patients at our center are coded preand postoperatively for degrees of hip pain, walking ability, range of motion and functional capacity. ${ }^{7}$

Epidural anaesthesia was used for surgery. All patients received cementless THR and surgery was performed in a lateral position through an anterolateral, transgluteal approach. One-stage bilateral surgery started on the most painful side. After closing the wound on first side, patient was turned over to the other side and dressed before being operated upon the other side. The time from the last skin staple on the first hip to the skin incision of the second hip was 15 to 20 minutes. One suction drain was placed in each hip for post-operative drainage.

The operating time, intra-operative blood loss, and any intra-operative complications were recorded. The operating time was calculated as the time between the induction of anaesthesia and skin closure on the second hip. Intra-operative blood loss was estimated by measuring the volume of blood in the suction bottles, weighing the swabs used and deducting the volume of irrigation fluid. Total blood loss was calculated as the sum of the estimated intra-operative blood loss and the blood collected in the suction drains in the first 48 hours. The length of hospital stay was calculated from the day of operation until discharge. Total number of blood transfusions done intra operatively and post operatively were recorded.

Preoperative prophylaxis against infection was given to all patients (Ceftriaxone $1 \mathrm{~g}$ intravenously before the surgery followed by $1 \mathrm{~g} 2$ times daily till discharge). Subcutaneous low molecular weight heparin (40 mg once daily) starting on the day of surgery was given to all patients for 7 days in addition to antiembolism stockings as prophylaxis against deep vein thrombosis (DVT). Oral aspirin (150 mg once daily) was given for four weeks after the discontinuation of enoxaparin. No routine screening for DVT was performed, but Doppler ultrasonography was carried out if DVT was suspected. Mobilization of limb was started on the next post op day and was advised to do static quadriceps and isometric hamstring exercises. Partial weight bearing with walker was started on 2nd post-operative day after removal of drain. Sutures were removed on 12th post-operative day. Abductors strengthening exercises were advised after suture removal. Full weight bearing was allowed at 6 weeks. Those with ankylosing spondylitis received oral indomethacin, $25 \mathrm{mg}$ three times daily for three weeks as prophylaxis against heterotopic ossification.

One unit blood transfusion was done irrespective of the blood loss. Post operatively hemoglobin was measured on $2^{\text {nd }}$ day post op and the transfusion requirement were assessed by the surgeon by intraoperative blood loss, clinical and hematological parameters. Complications local to each joint including fracture, dislocation, superficial wound infection, deep wound infection around the prosthesis and incidence of heterotopic ossification were recorded. Systemic complications including cardiac, gastrointestinal complications, cerebrovascular accidents, phlebitis/pulmonary embolism, and urinary tract infection were also noted. Patient assessment was undertaken preoperatively and again postoperatively using a clinical hip score based upon the modified Harris Hip Score (MHHS) and VAS score. ${ }^{8}$ We asked the patients, whether they would go for the same surgery procedure and if they would recommend it to others. Patients' satisfaction evaluation was used as a good factor, distinguishing the procedure from others. 


\section{RESULTS}

Statistical analysis was done using $\mathrm{R}$ programming software. The mean age of patients undergoing bilateral total hip replacement was $40 \pm 2.5$ (range 21 to 68) (Table 1). The 21-year-old patient had AVN of hip and the 68year-old had bilateral osteoarthritis of hip joint. Male female ratio was $2: 1$. The etiology of the hip diseases has been illustrated in Figure 1. There were no significant differences between hemoglobin level and ASA grade postoperative. The parameters of the study participants have been tabulated in Table 2 .

Table 1: distribution of study participants according to age.

\begin{tabular}{|l|l|}
\hline \hline Age group (in years) & Number of patients \\
\hline $\mathbf{2 1 - 4 0}$ & 13 \\
\hline $\mathbf{4 1 - 6 0}$ & 9 \\
\hline $\mathbf{6 1 - 8 0}$ & 2 \\
\hline
\end{tabular}

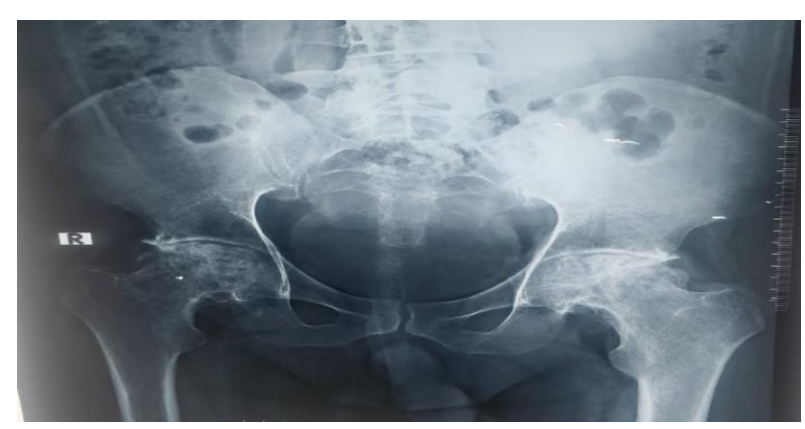

Figure 1: Indications of bilateral THR in study participants.

Table 2: Pre, intra and post-operative parameters of study patients.

\begin{tabular}{|lll|}
\hline Parameters studied & Mean & $\begin{array}{l}\text { Standard } \\
\text { deviation }\end{array}$ \\
\hline Age of patients (in years) & 40 & \pm 2.5 \\
\hline $\begin{array}{l}\text { Duration of surgical } \\
\text { procedure (in minutes) }\end{array}$ & 112 & \pm 5.12 \\
\hline $\begin{array}{l}\text { Pre-operative hemoglobin } \\
\text { level (g/dl) }\end{array}$ & 13.83 & \pm 0.3 \\
\hline $\begin{array}{l}\text { Intra-operative blood loss (in } \\
\text { mL) }\end{array}$ & 1347 & \pm 75 \\
\hline $\begin{array}{l}\text { Post-operative blood loss in } \\
\text { drain (in ml) }\end{array}$ & 260 & \pm 20 \\
\hline $\begin{array}{l}\text { Post-operative hemoglobin } \\
\text { level (g/dl) }\end{array}$ & 10.83 & \pm 0.3 \\
\hline $\begin{array}{l}\text { mean pre-operative MHHS } \\
\text { score }\end{array}$ & 45.93 & \pm 5.33 \\
\hline $\begin{array}{l}\text { mean post-operative MHHS } \\
\text { score }\end{array}$ & 92.06 & \pm 2.47 \\
\hline
\end{tabular}

There was no reported patient with perioperative death, deep venous thrombosis, pulmonary embolism, dislocation, periprosthetic fracture or heterotrophic ossification. No patient required reoperation. However, one of the patients, developed unilateral, temporary peroneal nerve palsy (1.6\%) which resolved after 3 months and one patient developed superficial wound infection which healed on oral antibiotics in 2 weeks after suture removal. All the complications occurred while the patients were still admitted in the hospital. There were no patients with deep vein thrombosis or pulmonary embolism.

The mean duration of hospital stay was 7 days post op. The mean preoperative MHHS score was $45.93 \pm 5.33$ in patients. MHHS score improved to $92.06 \pm 2.47$ by the last follow-up. There were no significant differences between MHHS score and ASA grade $(p=0.76)$. There was no radiographic evidence of loosening or periprosthetic dislocation in any THA studied. The mean VAS score was 23 and it improved to 28 by the last follow up. The mean range of flexion was improved from $55^{\circ}$ to $110^{\circ}$ after operation. Postoperatively, all patients (100\%) reported satisfaction with the surgery, increased function and reported either no pain or a small amount of pain but no compromise in activities. All of them (100\%) would recommend the surgery procedure to others with similar problems.

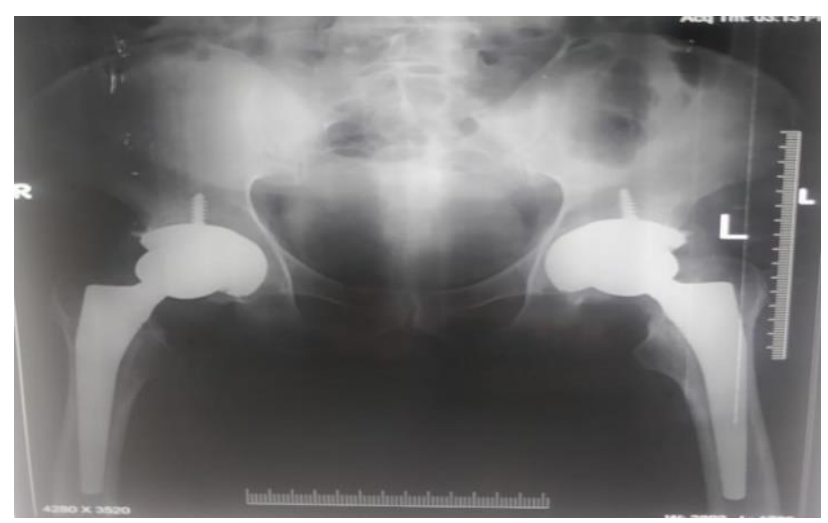

Figure 2: Preoperative AP radiograph of bilateral AVN hip joint.

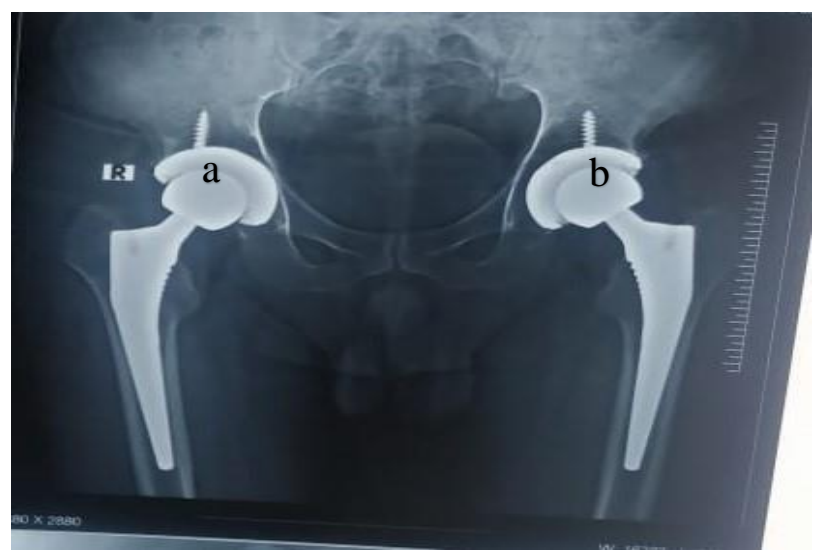

Figure 3: (a) Postoperative AP radiograph of bilateral THR patient, (b) postoperative AP radiograph of bilateral THR patient at 1.5 years' follow-up. 


\section{DISCUSSION}

Ever since Charnley first implemented one-stage bilateral THA, many studies have been conducted to address the controversial risks and benefits of one-stage bilateral THA about complications and higher transfusion rates. Our results indicated that clinical outcome of one stage bilateral THA is comparable to that of unilateral THA. ${ }^{9}$

We had all three ASA grades of patients in our study, and none of them had any systemic complications intraoperatively and immediate postoperative period. Alfaro-Adrian et al. ${ }^{10}$ reported a higher incidence of periand post-operative complications in patients with significant co-morbidities (ASA grade 3 and grade 4) whether the operation was staged or conducted as a single procedure.

The time of surgery for single stage bilateral THA was much less as compared to staged bilateral THA as mentioned by the study of Bhan et al the time was 217 mins. According top Bhan et al the intraoperative blood loss totally in single stage bilateral THA (1473 ml) was less than staged sequential bilateral THA (1997). ${ }^{11}$ Our study results showed a total intraoperative blood loss of $900 \mathrm{ml}$ which is lesser than the Bhan et al study. ${ }^{11} \mathrm{We}$ transfused one unit of whole blood component regardless of the hematocrit value, whereas further transfusions were decided depending upon the post op hematocrit values. Observations made by Salvati et al and AlfaroAdrian et al showed that the transfusion requirements were less in staged bilateral THA than in simultaneous THA. $^{12}$

We found that there was significant difference in the functional outcome of bilateral THA, [as evaluated by the MHHS and range of movement] when compared to those of unilateral THA in patients with bilateral hip disease. ${ }^{13}$ Our results are similar to the report by Wykman et al who found suboptimal gain in the range of movement and improvement in gait in patients undergoing bilateral THA. ${ }^{5}$

There has been evidence of increase in rate of heterotropic ossification in patient who underwent single stage bilateral THA, by study of Ritter and Vaughan, but our study population did not show any such complications. ${ }^{14}$ A study by Linda et al showed that there was $5.8 \%$ incidence of superficial infection in simultaneous bilateral THR, whereas Houtari et al showed that there was no significant difference between unilateral and bilateral THA in terms of infection. ${ }^{15,16}$ In contrast to the current study, some previous studies have demonstrated a higher incidence of thromboembolic events in patients who underwent simultaneous bilateral THA. ${ }^{17}$ Recently, Otte et al demonstrated a high complication rate $(22 \%)$ after simultaneous bilateral THA. ${ }^{18}$ There was a significant increase in rates of reoperation, pulmonary problems in single stage bilateral THA as shown by two studies, i.e., Berend et al. ${ }^{19,20}$ This study also concluded that the rehabilitation programme for these patients were to be difficult. A study by Glait et al compared the unilateral and single stage bilateral THA and found that risk of thromboembolic events and the duration of hospital stay were higher in simultaneous procedures. ${ }^{21}$

Hip diseases have been one of the major treatable cause of productivity loss. The time required for the gain in quality of life is increased in staged bilateral THA than in Single stage bilateral THA. Shorter duration of hospital stays and lesser rehabilitation time is the main advantage to a patient from an upper middle and lower class of family, especially when the patient himself is the only earning person in family.

One major concern for health care is how to reduce productivity loss and other economic consequences attributable to hip disease. Longer sick leave is associated with decreased return to work, and this supports single stage procedure. ${ }^{22}$

\section{CONCLUSION}

The combination of lower total hospital cost and shorter duration of hospital stay, with no significant difference in complication rate, concludes that single stage bilateral THA is safe and cost effective in a hospital setting where there is a good multi departmental cooperation and a resident doctor is available round the clock for the management of complications.

Funding: No funding sources Conflict of interest: None declared

Ethical approval: The study was approved by the institutional ethics committee

\section{REFERENCES}

1. Ritter MA, Randolph JC. Bilateral total hip arthroplasty: a simultaneous procedure. Acta Orthop Scand. 1976;47:203-8.

2. Salvati EA, Hughes P, Lachiewicz P. Bilateral total hip-replacement arthroplasty in one stage. J Bone Joint Surg [Am]. 1978;60-A:640-4.

3. Ritter MA, Stringer EA. Bilateral total hip arthroplasty: a single procedure. Clin Orthop 1980;149:185-90.

4. Camissa FPJ, O’Brien SJ, Salvati EA, Sculco TP, Wilson PD Jr, Ranawat CS, et al. One-stage bilateral total hip arthroplasty: a prospective study of perioperative morbidity. Orthop Clin North Am. 1988;19:657-68.

5. Wykman A, Olsson E. Walking ability after total hip replacement: a comparison of gait analysis in unilateral and bilateral cases. J Bone Joint Surg [Br]. 1992;74-B:53-6.

6. Shih $\mathrm{CH}$, Ho WB. One-stage versus two-stage bilateral autophor ceramic total hip arthroplasty. Clin Orthop. 1985;193:141-5. 
7. Wilson PD, Amstutz HC, Czerniecki A, Salvati EA, Mendes DG. Total hip replacement with fixation by acrylic cement. A preliminary study of 100 consecutive McKee-Farrar prosthetic replacements. J Bone Joint Surg Am. 1972;54(2):207-36.

8. Wamper KE, Sierevelt IN, Poolman RW, Bhandari M, Haverkamp D. The Harris hip score: Do ceiling effects limit its usefulness in orthopedics: A systematic review. Acta Orthopaedica. 2010;81:7037 .

9. Sivananthan S, Arif M, Choon DS. Small stem Exeter total hip replacement: clinical and radiological follow-up over a minimum of 2.5 years. J orthop Surg. 2003;11:148-53.

10. Brooker AF, Bowerman JW, Robinson RA, Riley LH Jr. Ectopic ossification following total hip replacement: incidence and a method of classification. J Bone Joint Surg [Am]. 1973;55(A):1629-32.

11. Bhan S, Pankaj A, Malhotra R. One- or two-stage bilateral Total Hip Arthoplasty. J Bone Joint Surg (Br). 2006;88B:298-303.

12. Adrian AJ, Bayona F, Rech JA, Murray DW. One or two-stage bilateral total hip replacement. J Arthroplasty. 1999;14:439-45.

13. Lindberg L, Sjostrand LO. The future needs of hip surgery. Prognosis for Lund 1972-1980. Lakartidningen. 1972;69:4109-12.

14. Ritter MA, Vaughan RB. Ectopic ossification after total hip arthroplasty: predisposing factors, frequency, and effect on results. J Bone Joint Surg [Am]. 1977;59:345-51.

15. Johnston LR, Clift BA, Abboud RJ. Bilateral Simultaneous Hip Replacement Versus Bilateral
Sequential Hip Replacement: A 7-Year Data Review. Orthop Nurse. 2011;30(2):119-23.

16. Huotari K, Lyytikainen O, Seitsalo S. Patient outcomes after simultaneous bilateral total hip and knee joint replacements. J Hosp Infect. 2007;65:219-25.

17. Bracy D, Wroblewski BM. Bilateral Charnley arthroplasty as a single procedure. A report on 400 patients. J Bone Joint Surg Br. 1981;63:354-46.

18. Otte KS, Husted H, Orsnes T, Kehlet H. Bilateral simultaneous total hip arthroplasty in a fast track setting. Hip Int. 2011;21:336-9.

19. Berend KR, Lombardi AV, Adams JB. Simultaneous vs staged cementless bilateral total hip arthroplasty: perioperative risk comparison. J Arthroplasty. 2007;22:111-5.

20. Berend ME, Ritter MA, Harty LD, Davis KE, Keating EM, Meding JB, et al. Simultaneous bilateral versus unilateral total hip arthroplasty an outcomes analysis. J Arthroplasty. 2005;20:421-6.

21. Lindberg L, Sjostrand LO. The future needs of hip surgery. Prognosis for Lund [1972-1980]. Lakartidningen. 1972;69:4109-12.

22. Kuoppala J, Lamminpaa A. Rehabilitation and work ability: a systematic literature review. J Rehabil Med. 2008;40:796-804.

Cite this article as: Meena RP, Shetty U, Bishnoi S, Meena R. Functional outcomes and complications of simultaneous bilateral total hip arthroplasty in Asian population. Int J Res Orthop 2020;6:369-73. 